\title{
PET Superscan Caused by Lung Cancer
}

\author{
Hiromichi Yamane, Nobuaki Ochi, Yoshihiro Honda and Nagio Takigawa
}

Key words: lung cancer, FDG-PET, superscan, bone metastasis

(Intern Med 54: 2951, 2015)

(DOI: 10.2169/internalmedicine.54.5211)
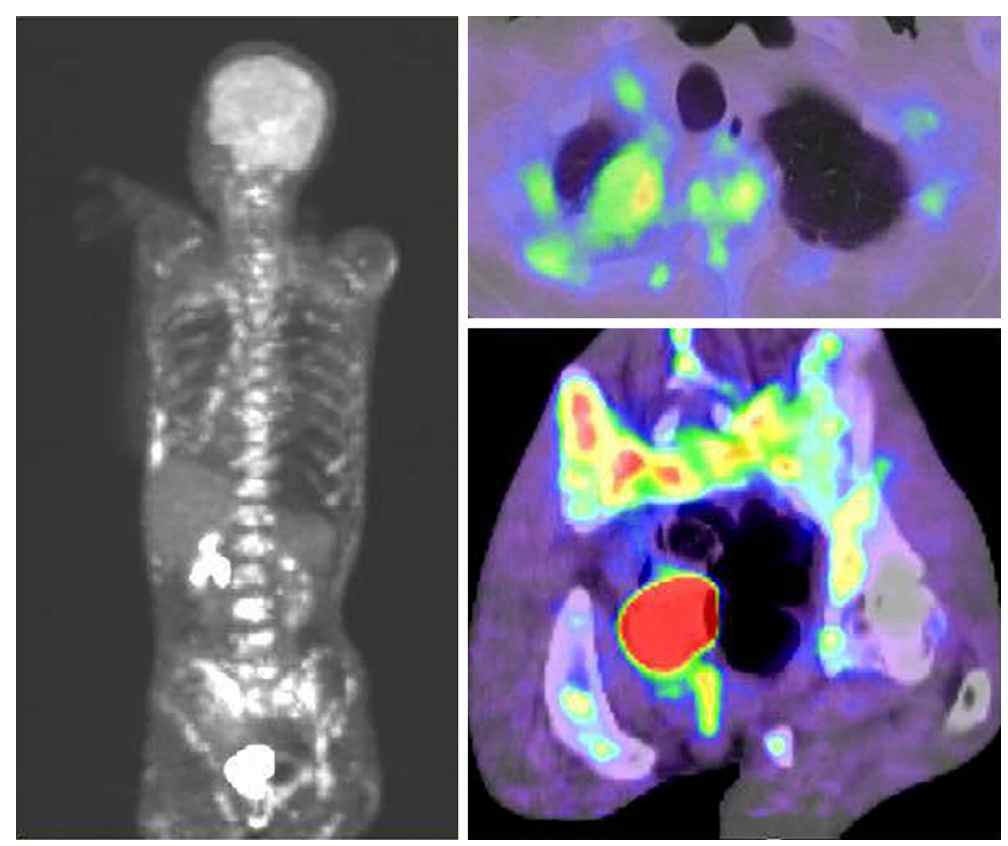

Picture.

A 58-year-old man presented with severe lumbago. Three months earlier he had visited an orthopedist, where he had been diagnosed with postoperative neuropathic pain due to lumbar disc herniation. Fluorodeoxyglucose-positron emission tomography/computed tomography (FDG-PET/CT) revealed a mass lesion with the uptake of FDG in the right upper lobe of the lung. Widespread hypermetabolic lesions were also observed in the bone marrow throughout the skeleton, involving the ribs, thoraco-lumbar spine, and pelvic bones, or so called "superscan" (Picture). It resembled a "superscan" pattern of multiple metastases on ${ }^{99 \mathrm{~m}} \mathrm{Tc}$ bone scintigraphy. A biopsy of the iliac bone marrow showed a poorly differentiated adenocarcinoma that was strongly posi- tive for thyroid transcription factor-1. Although bone marrow carcinosis is rare (1), physicians should be aware of this condition and the corresponding radiological findings on FDG-PET.

The authors state that they have no Conflict of Interest (COI).

\section{Reference}

1. Buckley O, O'Keeffe S, Geoghegan T, et al. $99 \mathrm{mTc}$ bone scintigraphy superscans: a review. Nucl Med Commun 28: 521-527, 2007.

Department of General Internal Medicine 4, Kawasaki Medical School, Japan

Received for publication February 23, 2015; Accepted for publication March 29, 2015

Correspondence to Dr. Hiromichi Yamane, hiromichi.ya@gmail.com

(C) 2015 The Japanese Society of Internal Medicine Journal Website: http://www.naika.or.jp/imonline/index.html 